\title{
Honeybee colony losses in Uruguay during 2013-2014
}

\author{
Karina AntúnEz ${ }^{1}$, Ciro Invernizzi ${ }^{2}$, Yamandú MendozA ${ }^{3}$, Dennis vanEngelSDORP ${ }^{4}$, \\ Pablo ZunINo ${ }^{1}$ \\ ${ }^{1}$ Departamento de Microbiología, Instituto de Investigaciones Biológicas Clemente Estable, Avda. Italia 3318, 11600, \\ Montevideo, Uruguay \\ ${ }^{2}$ Sección Etología, Facultad de Ciencias, Universidad de la República, Montevideo, Uruguay \\ ${ }^{3}$ Sección Apicultura, Instituto Nacional de Investigación Agropecuaria, Colonia, Uruguay \\ ${ }^{4}$ Department of Entomology, University of Maryland, College Park, MA, USA
}

Received 29 December 2015 - Revised 21 June 2016 - Accepted 9 November 2016

\begin{abstract}
High rates of honey bee colony losses have been reported worldwide; however, data about colony loss rates in South America is scarce. This study quantified colony losses experienced in Uruguay during the 2013-2014 season and identifies the self-diagnosed causes for these losses. An estimated $2.6 \%$ of all Uruguayan beekeepers, who collectively managed $5 \%$ of the estimated 550,000 colonies in the country, responded to this survey. We found that total summer and winter losses were similar (summer 19.0\% (95\% CI 13.26-24.77\%), winter 20.2\% (95\% CI 14.98-25.39)), as were the average operational losses (summer 19.8\% (95\% CI 14.01-25.52), winter 18.3\% (95\% CI 13.15-23.56\%)). The total annual loss was $28.5 \%$ (95\% CI 22.42-34.51\%), with each beekeeper losing, on average, $28.6 \%$ (95\% CI 22.52-34.61\%) of the colonies in their operation. Loss rates were similar across operations of different sizes. Queen failure, diseases and parasites, and pesticides were the leading self-reported and selfdiagnosed causes of colony losses. This study is the first to document honey bee colony losses in Uruguay, establishing a baseline for future long-term monitoring.
\end{abstract}

honey bee colony losses / South America / Africanized honey bee / Apis mellifera / questionnaire / surveillance

\section{INTRODUCTION}

Over the last decade, high rates of managed honey bee colony losses have been reported worldwide. These reports have almost exclusively included countries in the northern hemisphere including North America and several European countries (Ellis et al. 2010; Neumann and Carreck 2010; Potts et al. 2010; Steinhauer et al. 2014; van der Zee et al. 2014; Lee et al. 2015). High rates of colony losses are of concern because

Electronic supplementary material The online version of this article (doi:10.1007/s13592-016-0482-2) contains supplementary material, which is available to authorized users.

Corresponding author: K. Antúnez, kantunez03@gmail.com

Manuscript editor: Yves Le Conte bees play such a central role in pollinating many agricultural crops. Unmitigated and continued high rates of loss threaten the livelihood of the beekeepers who make a living keeping them and also are a risk to long-term food security (Stokstad 2007).

Information about honey bee colony losses in countries in the southern hemisphere is scarce (Vandame and Palacio 2010). The one known exception is South Africa (Pirk et al. 2014). In this work, authors reported high winter colony losses in 2009-2010 (29.6\%) and in 2010-2011 (46.2\%). While Argentina, Brazil, Uruguay, and Chile had reports of sporadic high rates of losses, or isolated examples of large-scale losses (Antunez et al. 2005, 2006; Maggi et al. 2013, Teixeira et al. 2008, 2012; Rodríguez et al. 2012), these reports are not the result of systematic nationwide surveys. 
Uruguay is a relatively small South American country $\left(176,000 \mathrm{~km}^{2}\right)$ with about 3000 registered beekeepers who collectively manage about 550,000 colonies. Honey is the primary source of income for most of Uruguayan beekeepers, who produce approximately $12,000 \mathrm{t}$ of honey per year (DIGEGRA-MGAP 2016). Most of this honey $(\sim 95 \%)$ is exported to supply markets in the USA, Germany, Spain, and other European countries.

Uruguayan beekeepers manage European honey bees, hybrids of races originating in Europe (e.g., Apis mellifera mellifera, A. m. ligustica) or Africanized bee hybrids (derived from $A$. $m$. scutellata) (Burgett et al. 1995; Diniz et al. 2003). Currently, Africanized bees are widely distributed in the country, representing approximately $80 \%$ of the colonies (Branchiccela et al. 2014).

Many important honey bee parasites and pathogens are present and widely distributed in Uruguay including Varroa destructor, Nosema ceranae, and many RNA viruses (ABPV, BQCV, CBPV, DWV, and SBV) (Anido et al. 2016; Antunez et al. 2005, 2006, 2015; Invernizzi et al. 2009). Other bee pathogens, such as Paenibacillus larvae, the causative agent of American foulbrood, Melissococcus pluton, the causative agent of European foulbrood, and Ascosphaera apis, the causative agent of Chalkbrood disease, are also present. Clinical infections with these pathogens occur relatively infrequently and are not thought to represent an important threat to the beekeeping industry (Antunez et al. 2012; Invernizzi et al. 2011). Additionally, there have been documented cases of pesticide kills, specifically from fipronil and imidacloprid exposure (Pareja et al. 2011). The aim of the present study was to quantify colony losses in Uruguay during the period 2013-2014 and to identify potential causes of these losses.

\section{MATERIALS AND METHODS}

A Spanish language questionnaire (see Supplementary Material) was designed, based on the survey carried out by the Bee Informed Partnership (Steinhauer et al. 2014) and the COLOSS questionnaire (van der Zee et al. 2012) (Supplementary Material). Respondents were asked to answer questions that would allow for the calculation of loss rates and those that could help identify risk factors associated with these loss rates such as management practices, productivity, and self-identified and diagnosed causes of losses.

The questionnaire was distributed between October 1, 2014, and March 1, 2015. We included in our analysis any questionnaires returned before April 1, 2015. To ensure we received responses from a diverse array of respondents, we distributed the survey using several different channels including e-mailing copies to beekeepers and paper copies delivered by hand at beekeeper meetings. E-mails asking beekeepers to participate in this survey were sent to the membership of the national beekeepers association (Sociedad Apícola del Uruguay), as well as any beekeeper known by the Commission for the Development of Beekeeping (CHDA); the National Commission of Rural Development (CNFR); the Association of Honey Exporters (ADEXMI); the Ministry of Livestock, Agriculture and Fishing; the Instituto Nacional de Investigación Agropecuaria; the Instituto de Investigaciones Biológicas Clemente Estable; the Facultad de Ciencias; the Facultad de Veterinaria; and the Facultad de Agronomía. Paper surveys were distributed at two different beekeeper meetings $(n=2)$ and two different bee courses $(n=2)$. In all, we estimate that around 700 beekeepers received a request to complete our survey.

Once received, completed survey responses were transcribed into an excel sheet to permit further analysis. Once compiled, the data were cleaned to correct for obvious entry errors and to exclude any data from respondents who gave insufficient data to allow for loss calculations or provided invalid responses. Not all beekeepers answered all the questions, and so loss rates over the summer, winter, and entire year could not be calculated for all beekeepers. We only included responses in a given period when losses could be calculated for a respondent for that period. We calculated both the average and total loss rate experienced by beekeepers for the summer, winter, and entire year (vanEngelsdorp et al. 2013).

By grouping beekeepers according to the size of their operation (on October 1, 2013: small (0$100)$, medium (100-500), and large operation 
(more than 500)), we were able to explore potential differences in loss rates reported by different groups of beekeepers using the Kruskal-Wallis rank sum test or the Mann-Whitney test. The same tests were used to compare loss rates between beekeepers who practiced or did not practice different management practices (moved bees, feeding, queen replacement, comb replacement, etc.) (vanEngelsdorp et al. 2010).

\section{RESULTS}

\subsection{Responding beekeeper demographics}

A total of 78 valid responses were received, comprising $2.6 \%$ of the total beekeeper population of Uruguay. Responding beekeepers reportedly managed 25,527 colonies, or $\sim 5.1 \%$ of the estimated total number of colonies managed in the country on October 1, 2014.

The vast majority of responding beekeepers (71.4\%) reported that beekeeping was their primary source of income. On average, responding beekeepers reported that they kept bees $18.1 \pm 10.46$ years (range $1-48$ years). Forty percent of respondents belong to at least one beekeeper group that provided technical support, while $92.3 \%$ attended a beekeeping meeting at least once over the previous year.

The majority of beekeepers $(98.6 \%)$ reported that they managed "local" Africanized honey bee hybrids, while $11.1 \%$ also kept local European race hybrid (mainly $A$. $m$. ligustica). The average responding beekeeper managed $416 \pm 63$ colonies.

\subsection{National losses}

Responding beekeepers reportedly lost $19.0 \%$ (95\% CI 13.26-24.77\%) of colonies over the summer, $20.2 \%$ (95\% CI 14.98-25.39) over the winter, and $28.5 \%$ (95\% CI $22.42-34.51 \%$ ) of their colonies over the entire year (Table I). Average losses tracked closely with total losses, with individual beekeepers losing an average $19.8 \%$ (95\% CI 14.01-25.52) of their colonies in summer, $18.3 \%$ (95\% CI 13.15-23.56\%) in winter, and $28.6 \%$ (95\% CI $22.52-34.61 \%$ ) over the entire year (Table I).
Table I. Self-reported 2013-2014 colony losses in Uruguay (total and average loss \%, 95\% CI).

\begin{tabular}{lll}
\hline Period & $\begin{array}{l}\text { Total loss } \\
(\%(\mathrm{CI}))\end{array}$ & $\begin{array}{l}\text { Average loss } \\
(\%(\mathrm{CI}))\end{array}$ \\
\hline Summer loss & $19.0(13.26-24.77)$ & $19.8(14.01-25.52)$ \\
Winter loss & $20.2(14.97-25.39)$ & $18.3(13.14-23.56)$ \\
Annual loss & $28.5(22.42-34-51)$ & $28.6(22.52-34.61)$
\end{tabular}

Summer loss represents loss between October 1, 2013, and April 1, 2014; winter loss between April 1, 2014, and October 1, 2014; and annual loss between October 1, 2013, and October 1, 2014

\subsection{Losses by operation size}

Most beekeepers who responded to this survey (50.9\%) ran medium-sized operations (between 101 and 500 colonies), with small-scale beekeepers (managing less than 100 colonies) and large beekeepers (managing more than 500 colonies) representing 21.0 and $28.1 \%$ of the response pool, respectively. Loss rates were similar among the different sized operations (total loss comparison: Kruskal-Wallis test $p>0.05$ and average loss comparison: Mann-Whitney test $p>0.05$ ) (Figure 1).

\subsection{Management practices and loss rates}

Over half $(56.0 \%)$ of responding beekeepers reported moving their colonies in 2014. Most of those moving colonies (52.9\%) reportedly did so to take advantage of honey flow from Eucalyptus sp. plantations in the north of the country. Beekeepers who moved their bees did not lose more or fewer colonies than those who did not move (Mann-Whitney test $p>0.05$ ). We also found no differences between the loss rates of beekeepers who reportedly feed or did not feed carbohydrates or protein or reportedly replaced their colony queens over the course of the season. As all respondents performed comb replacement, it was not possible to compare loss rates between those who use this management practice and those who do not.

Most beekeepers (87.2\%) reported buying new colonies or splitting their own colonies during summer (October 2013-April 2014) while only 


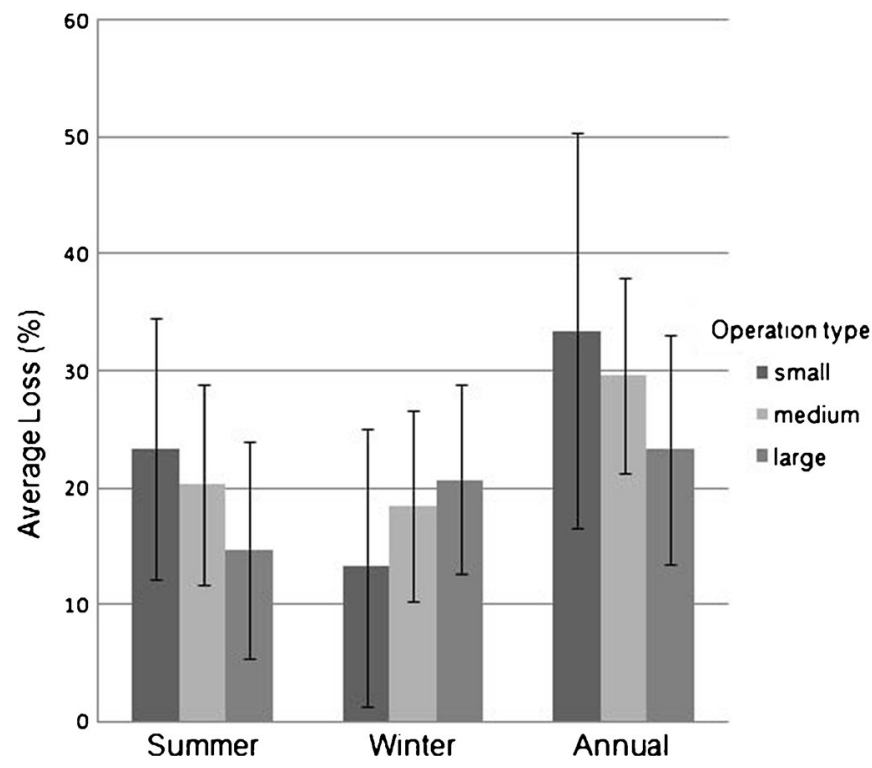

Figure 1. Self-reported 2013-2014 colony losses in Uruguay (average loss \%, 95\% CI) according to operation size: small (0-100 colonies), medium (100-500 colonies), and large operation (more than 500 colonies). Summer loss represents loss between October 1, 2013, and April 1, 2014; winter loss between April 1, 2014, and October 1, 2014; and annual loss between October 1, 2013, and October 1, 2014.

9.1\% reported engaging in this activity during the winter (April 2014-October 2014). Splitting and buying new colonies increased the number of colonies in responding beekeepers' operations by $25.7 \%$ in summer and $1.7 \%$ in winter. These increases match closely with the total annual loss rate of $28.5 \%$.

\subsection{Causes of colony losses}

Responding beekeepers most frequently selfidentified the causes of colony losses as queen failure (55.8 and $59.6 \%$ for summer and winter, respectively), diseases and parasites (44.2 and $61.5 \%$ for summer and winter, respectively), and pesticide poisoning ( 40.4 and $32.7 \%$ for summer and winter, respectively); however, no differences in colony losses were detected between beekeepers who reported or did not report a specific cause ( $p>0.05$ in all cases).

\subsection{Varroa destructor control practices}

The vast majority of beekeepers $(98.6 \%)$ reported the presence of the mite $V$. destructor in their colonies during the period, and all beekeepers applied acaricides, mainly synthetic acaricides (amitraz, $61.3 \%$ of respondents and flumethrin, $35.5 \%$ of respondents), while some used only organic-based products $(9.7 \%$, oxalic acid and/or thymol). About a third of respondents $(38.7 \%)$ reportedly used both organicbased and synthetic acaricides. Most beekeepers $(84.6 \%)$ reportedly checked mite levels after treatments to ensure treatment efficacy. No difference was detected in average annual or winter colony losses between beekeepers who used synthetic, organic-based, or both acaricides (Mann-Whitney test $p>0.05$ ). Since all beekeepers applied acaricides, we could not compare the loss rates between beekeepers who treated for $V$. destructor and those who did not.

Nosemosis was the second most commonly reported disease condition reported (51.6\%), and those who reported this condition had higher annual loss rates than those who did not (average loss $35.8 \%$ (95\% CI $26.1-45.5$ ) vs. $23.3 \%$ (95\% CI 16.9-29.7) respectively, Mann-Whitney test: $U=70.50 ; p=0.05$ ). 
Just over $16 \%$ of beekeepers reported seeing clinical signs of viral infection in their operations, with those reporting the condition losing significantly more colonies over the year than those who did not $(52.4 \%$ (95\% CI 30.3-74.4) and $25.4 \%$ (95\% CI 20.7-30.1) respectively, Mann-Whitney test: $U=23.00 ; p=0.02$ ).

Beekeepers self-reported low occurrence of clinical American foulbrood (3.2\% of operations) but a high incidence of clinical European foulbrood infections (19.3\% of operations); however, beekeepers reporting these conditions did not experience loss rates that were different from their counterparts who did not report having these conditions (Mann-Whitney test $p>0.05$ ).

\section{DISCUSSION}

This is the first survey of summer, winter, and annual colony loss rates in Uruguay. The total and average loss rates estimated from the survey (about $19 \%$ of summer and winter and $28 \%$ of annual losses) were higher than expected, considering that previous reports suggested that the continent had not experienced high rates of loss (Vandame and Palacio 2010). Further, the high rate of loss was unexpected because in Uruguay colony, numbers have remained stable over the years proceeding this survey (an average of 550,000 colonies between 2012 and 2014) (DIGEGRA, MGAP 2016).

Our data support the conjecture that when high losses occur, these losses do not necessarily translate to declines in overall honey bee populations. The ability of beekeepers to quickly replace dead colonies may mask loss rate severity (vanEngelsdorp and Meixner 2010). In fact, $88.9 \%$ of responding beekeepers reported that they had bought new colonies or split their own during this period. In total, these beekeepers added $29.4 \%$ more colonies to their operations, nearly completely making up for colonies they reportedly lost over the same period $(28.5 \%)$.

The total colony loss rates reported here are similar to those described for USA during the summer of 2013, the winter of 2013-2014, and the annual loss for that same time period (19.8, 23.7 , and $34.1 \%$, respectively, Lee et al. 2015).
Uruguayan beekeepers did suffer elevated total winter losses compared to total winter (20132014) losses reported in 19 European countries (ranging from 6\% in Norway to $14 \%$ in Portugal; van der Zee et al. 2014); however, caution must be taken when making this comparison because the European survey does not standardize the time period used to define "winter," leaving it for responding beekeepers to self-define this period. Our numbers represent losses incurred over a defined timeframe of 6 months. Regardless, this comparison highlights the importance of the present study, the first systematical study of colony losses in South America, and demonstrates that high colony loss rates also occur in the southern hemisphere. More studies should be carried out in South America to evaluate the extent of the problem.

The causes of colony losses self-identified by beekeepers in this study were (1) queen failure, (2) disease and parasites, and (3) pesticides. Most beekeepers reported the presence of $V$. destructor in the colonies $(96.8 \%)$, confirming a previous study that found a high prevalence $(75.7 \%)$ and wide distribution of $V$. destructor nationally (Anido et al. 2016). Half of responding beekeepers reported clinical signs of Nosema spp. infection in their colonies, and those beekeepers lost significantly more colonies than those who did not. These finding also corroborates previous work, which found that $V$. destructor and Nosema spp. (N. ceranae) infections are a major cause of colony loss in Uruguay (Antunez et al. 2015).

While beekeepers in our survey reported pesticides as the third most important driver of bee loss, those who did report pesticides as a reason for loss did not lose more colonies than those who did not. However, this is not to say pesticides have no effect, as previous studies found a relationship between dead colonies and the presence of imidacloprid and fipronil (Pareja et al. 2011).

Queen failure was identified as the leading cause of colony losses in our survey, a result similar to that of US beekeepers (vanEngelsdorp et al. 2013). Unlike in the USA, however, this survey found no difference in colony loss rates reported by beekeepers who self-identified this potential cause of loss and those who did not. 
Unlike other studies in other regions (Lee et al. 2015), we did not find a difference in mortality rates when the respondent pool was segregated by operation size. We also did not find a difference in colony loss rates between migratory and nonmigratory operations.

Despite a multipronged and extensive recruitment effort, the response rate to our survey was low; about $3 \%$ of the beekeepers in Uruguay participated in this survey. These beekeepers managed about $5 \%$ of the colonies of the country. This response rate is comparable to the responses in other surveillance efforts (van der Zee et al. 2014).

We selected October 1 to April 1 to estimate summer colony loss and April 1 to October 1 to estimate winter loss. This later period was selected because it encompasses the traditional inactive season of the colony (vanEngelsdorp and Pirk, pers. comm.); however, the length of the inactive season may vary if beekeepers relocate their colonies to Eucalyptus grandis plantations at the end of summer (February or March). Winter has always been seen as the period of the year with the highest mortality risk, but in the case of Uruguay, mortality during summer and winter is equivalent. These results confirm the finding of other authors who have noted the importance of capturing a complete picture of honey bee colony losses through surveys that document annual results (Steinhauer et al. 2014).

This study provides information regarding the extent and self-reported causes of colony losses in Uruguay, being the first nationwide survey carried out in South America, and establishes a baseline for future studies.

\section{ACKNOWLEDGEMENTS}

Authors thank Christian Pirk and Hannelie Human for advices on questionnaire and data analysis, Karen Rennich for review of the manuscript, and also the anonymous reviewers who helped improve it. Authors also thank Apis Uruguay (Walter Pastorin) for questionnaire design.

Contributions All authors participated in questionnaire design, results interpretation, and paper writing. KA also performed data collection and statistical analysis. DvE also collaborated with statistical analysis.
Pertes de colonies d'abeilles en Uruguay au cours des années 2013-2014

Apis mellifera / abeilles africanisées / Amérique du Sud / questionnaire / surveillance des colonies

\section{Bienenvolkverluste in Uruguay in den Jahren 2013- 2014}

\section{Honigbienen / Völkerverluste / Südamerika / afrikanisierte Bienen / Apis mellifera / Umfrage / Monitoring}

\section{REFERENCES}

Anido, M., Branchiccela, B., Castelli, L., Harriet, J., Campá, J., Zunino, P., Antúnez, K. (2016) Prevalence and distribution of honey bee pathogens in Uruguay. $\mathrm{J}$. Apic. Res., in press

Antunez, K., D’Alessandro, B., Corbella, E., Zunino, P. (2005) Detection of chronic bee paralysis virus and acute bee paralysis virus in Uruguayan honeybees. J. Invertebr. Pathol. 90: 69-72.

Antunez, K., D'Alessandro, B., Corbella, E., Ramallo, G., Zunino, P. (2006) Honeybee viruses in Uruguay. J. Invertebr. Pathol. 93, 67-70.

Antunez, K., Anido, M., Branchiccela, B., Harriet, J., Campa, J., and Zunino, P. (2012) American Foulbrood in Uruguay: twelve years from its first report. J. Invertebr. Pathol. 110, 129-131.

Antunez, K., Anido, M., Branchiccela, B., Harriet, J., Campa, J., Invernizzi, C. et al. (2015) Seasonal variation of honeybee pathogens and its association with pollen diversity in Uruguay. Microb. Ecol. 70, 522-533.

Branchiccela, B., Aguirre, C., Parra, G., Estay, P., Zunino, P., Antúnez, K. (2014) Genetic changes in Apis mellifera after forty years of Africanization. Apidologie 45, 752-756.

Burgett, M., Shorney, S., Cordara, J., Gardiol, G., Sheppard, W.S. (1995) The present status of Africanized honey bees in Uruguay. Am. Bee J. 135, 328-330.

DIGEGRA, MGAP (2016) Programa Nacional de Trazabilidad de la Miel http://www.mgap.gub. uy/trazabilidadmiel.htm Accessed 22 April 2016

Diniz, N.M., Soares, A.E.E., Sheppard, W.S., Del Lama M.A. (2003) Genetic structure of honeybee populations from southern Brazil and Uruguay. Genetics and Mol. Biol. 26, 47-52.

Ellis, J., Evans, J.D., Pettis, J. (2010) Colony losses, managed colony population decline, and Colony Collapse Disorder in the United States. J. Apic. Res. 49, 134-136.

Invernizzi, C., Santos, E., García, E., Daners, G., Di Landro, R., Saadoun, A., Cabrera, C. (2011) Sanitary and nutritional characterization of honeybee colonies in Eucalyptus grandis plantations. Arch. Zootec. 60, 1303-1314. 
Invernizzi, C., Abud, C., Tomasco, I.H., Harriet, J., Ramallo, G., Campa, J. et al. (2009) Presence of Nosema ceranae in honeybees (Apis mellifera) in Uruguay. J. Invertebr. Pathol. 101, 150-153.

Lee, K., Steinhauer, N., Rennich, K., Wilson, M., Tarpy, D., Caron, D. et al. (2015) A national survey of managed honey bee 2013-2014 annual colony losses in the USA. Apidologie, 46(3): 292-305

Maggi, M., Ruffinengo, S., Negri, P., Brasesco, C., Medici, S., Quintana, S. et al. (2013) The status of bee health and colony losses in Argentina.: Nova Publishing Group. ISBN: 978-1-62948-661-1

Neumann, P., Carreck, N.L. (2010) Honey bee colony losses. J. Apicult. Res. 49, 1-6.

Pareja, L., Colazzo, M., Perez-Parada, A., Niell, S., CarrascoLetelier, L., Besil, N. et al. (2011) Detection of pesticides in active and depopulated beehives in Uruguay. Int. J. Environ. Res. Public Health 8, 3844-3858.

Pirk, C., Human, H., Crewe, R., vanEngelsdorp, D. (2014) A survey of managed honey bee colony losses in the Republic of South Africa-2009-2011. J. Apic. Res. 53, 35.

Potts, S.G., Biesmeijer, J.C., Kremen, C., Neumann, P., Schweiger, O., Kunin, W.E. (2010) Global pollinator declines: trends, impacts and drivers. Trends Ecol. Evol. 25, 345-353.

Rodríguez, M., Vargas, M., Gerding, M., Navarro, H., Antúnez, K. (2012) Viral infection and Nosema ceranae in honey bees (Apis mellifera) in Chile. J. Apic. Res. 51, 285-287.

Steinhauer, N.A., Rennich, K., Wilson, M.E., Caron, D.M., Lengerich, E.J., Pettis, J.S. et al. (2014) A national survey of managed honey bee 2012-2013 annual colony losses in the USA: results from the Bee Informed Partnership. J. Apic. Res. 53, 1-18.

Stokstad, E. (2007) The case of the empty hives. Science $316,970-972$.
Teixeira, E.W., Chen, Y., Message, D., Pettis, J., Evans, J.D. (2008) Virus infections in Brazilian honey bees. J. Invertebr. Pathol. 99, 117-119.

Teixeira, E.W., Chen, Y., Message, D., Boncristiani, H., Pettis, J., Evans, J. (2012) Israeli acute paralysis virus in Africanized honey bees in southeastern Brazilian Apiaries. J. Apic. Res. 51, 282-284.

van der Zee, R., Gray, A., Holzmann, C., Pisa, L., Brodschneider R., Chlebo, R. et al. (2012) Standard survey methods for estimating colony losses and explanatory risk factors in Apis mellifera. In: V. Dietemann, J.D. Ellis, P. Neumann (Eds), The COLOSS BEEBOOK, Volume I: Standard methods for Apis mellifera research. J. Apic. Res. 52: doi:10.3896/IBRA.3891.3852.3894.3818

van der Zee, R., Adjlane, N., Drazic, M., Filipi, J., Danihlík, J., Vejsnæs, F. et al. (2014) COLOSS Press Release colony losses July 14 Appendix, National Colony Winter Loss Data 2013-2014

Vandame, R., Palacio, M.A. (2010) Preserved honey bee health in Latin America: a fragile equilibrium due to low-intensity agriculture and beekeeping? Apidologie 41, 243-255.

vanEngelsdorp, D., Meixner, M.D. (2010) A historical review of managed honey bee populations in Europe and the United States and the factors that may affect them. J. Invertebr. Pathol. 103 Suppl 1, S80-95.

vanEngelsdorp, D., Tarpy, D.R., Lengerich, E.J., Pettis, J.S. (2013) Idiopathic brood disease syndrome and queen events as precursors of colony mortality in migratory beekeeping operations in the eastern United States. Prev. Vet. Med. 108, 225-233.

vanEngelsdorp, D., Speybroeck, N., Evans, J.D., Nguyen, B.K., Mullin, C., Frazier, M. et al. (2010) Weighing risk factors associated with bee colony collapse disorder by classification and regression tree analysis. J. Econ. Entomol. 103, 1517-1523. 